Restaria, então, como espaço de classe média, que também se beneficiou das políticas econômicas da última década e se expandiu, a burocracia estatal e empresarial, o serviço público, a pequena propriedade fundiária e o pequeno comércio não vinculado aos oligopólios transnacionais.

Pois bem, o que essas considerações têm a ver com nossa reflexão?

Como sujeito social, político, moral e cultural, uma classe social tanto pode ser transformadora, quanto pode ser absorvida ideologicamente pela classe dominante. Para Chauí 2 , essa segunda opção foi que vingou e estaria na gênese da difusão da existência de uma "nova classe média" no Brasil, colocando uma questão política muito relevante: “...está definida menos por sua posição econômica e muito mais por seu lugar ideológico, que tende a ser contraditório" 2 (p. 131). Fragmentada, individualista e competitiva, raramente encontrando um interesse comum que a unifique, desprovida de um referencial econômico claro e assombrada pelo fantasma da instabilidade, essa "classe média" alimenta um imaginário de ordem e segurança e uma ideologia conservadora e reacionária. Essas características seriam reforçadas pelo ingresso no consumo de massa, que reforça a crença de que se faz parte de "nova classe média”, que aspira à ascensão à classe dominante e se distancia da classe trabalhadora. Para Chauí 2 (p. 131-2), "a divisão social das classes é sobredeterminada pela polarização entre a carência (das classes populares) e o privilégio (da classe dominante) [...] Visto que uma carência é sempre particular, ela se distingue do interesse, que pode ser comum, e do direito, que é sempre universal. Visto que o privilégio é sempre particular, não pode unificar-se num interesse comum e jamais pode transformar-se num direito, pois deixaria de ser privilégio".

Para a autora, aí residiria a grande "dificuldade para instituir no Brasil a democracia, que se define pela criação de novos direitos pela sociedadee sua garantia pelo Estado" 2 (p. 132).

Portanto, somente será possível dar continuidade e consolidar uma política democrática (como a sustentação de um sistema nacional de saúde público e universal) enfrentando essa estrutura social.

Entretanto, isso não pode ser feito apenas pelo Estado (com reformas urgentes: tributária, política e social), mas também com a práxis dessa "nova classe trabalhadora", que se pretende "nova classe média", que mesmo em meio às adversidades deveria encontrar novas formas de organização e de luta pela democracia, leia-se, por seus direitos, como já fez aliás, nas últimas décadas do século passado.

Permanece a questão: será que as atuais e vibrantes manifestações de rua, que recusam tudo o que está aí e clamam por seus direitos, que criaram um fato político importante no país, apesar da ira contra "a política" e as instituições democráticas, têm esse discernimento e capacidade inovadora?

A história dirá, mas estou torcendo pelo SIM.

1. Pochmann M. Políticas públicas e situação social na primeira década do século XXI. In: Sader E, organizados. Lula e Dilma: 10 anos de governos pós-liberais no Brasil. São Paulo: Boitempo/Rio de Janeiro: FLACSO Brasil; 2013. p. 145-56.

2. Chauí M. Uma nova classe trabalhadora. In: Sader E, organizados. Lula e Dilma: 10 anos de governos pós-liberais no Brasil. São Paulo: Boitempo/Rio de Janeiro: FLACSO Brasil; 2013. p. 123-34.

3. Chauí M. As manifestações de junho de 2013 na cidade de São Paulo. Teoria \& Debate 2013; (113). http://www.teoriaedebate.org.br/materias/nacio nal/manifestacoes-de-junho-de-2013-na-cidadede-sao-paulo (acessado em 04/Jul/2013).

http://dx.doi.org/10.1590/0102-311XC0061013

José Carvalho de Noronha

Instituto de Comunicação e Informação Científica e Tecnológica em Saúde, Fundação Oswaldo Cruz, Rio de Janeiro, Brasil. noronha@cict.fiocruz.br

\section{A "crítica", a História e o país que queremos: comentários à margem do texto de Paim}

A História é sempre o que foi, jamais o que poderia ter sido. Não tolera o condicional "se". A busca das gêneses de Bourdieu, citada por Paim, serve de ferramenta analítica para ajudar a entender "conflitos e os confrontos dos primeiros momentos”. Já as utopias, "as utopias consolam: é que, se elas não têm lugar real, desabrocham, contudo, num espaço maravilhoso e liso; abrem cidades com vastas avenidas, jardins bem plantados, regiões fáceis, ainda que o acesso a elas seja quimérico" 1 (p. XIII).

A nenhum democrata fez, faz ou fará gosto, celebrar o caráter ditatorial do Governo Vargas. Entretanto, foi a coalizão que o conduziu ao poder que estabeleceu e desenvolveu a previdência social no Brasil que, como ensinou Donnangelo 2 (p. 11), "adquiriram de um lado o sentido de conquista de direitos sociais pelos assalariados e, de outro, revelaram-se como parte de um processo de reatualização, pelo estado, das condições necessárias à preservação e aos desdobramentos da ordem social capitalista. Da perspectiva do assalariado, a política trabalhista de Vargas, tanto a de pre- 
vidência social como a trabalhista, equivaleram a uma resposta a reivindicações imediatamente referentes ao consumo de um mínimo de bens $e$ serviços, mas, pela própria dinâmica das relações de classe, potencialmente relativas à negação do sistema. Aquelas políticas correspondiam a um mecanismo de atenuação das tensões sociais e ao mesmo tempo garantia, como contrapartida adequada aos novos rumos da economia, o controle das condições relativas ao trabalho e ao trabalhador". A dupla dinâmica recorrerá em nossa história? Penso que sim.

Vargas, reconduzido ao governo democraticamente, chamou atenção para a "existência de uma aguda consciência das reivindicações sociais e dos anseios por melhores condições de vida" (apud Hamilton \& Fonseca 3, p. 809). Essas aspirações só poderiam ser atendidas com uma maior participação do Estado. Em 1953, cresciam de maneira avassaladora as pressões populares. No Congresso, tramitava uma proposta de reforma administrativa que incluía a criação do Ministério da Saúde. Na ocasião, foi aprovada por unanimidade a proposta do governo da criação do Ministério dos Serviços Sociais, englobando Saúde e Previdência. Nas palavras de Gustavo Capanema, líder do Governo, “...os assuntos federais de saúde dariam um ministério de segunda ordem tão mesquinho, que no quadro geral da administração, seria uma agência secundária da nossa vida política nacional" (apud Hamilton \& Fonseca 3, p. 814). A reação conservadora obriga Vargas a ampliar sua base parlamentar. Atendendo pleitos do Governador do Estado Rio, Amaral Peixoto, cria o Ministério da Saúde, separando as ações de saúde da educação, porém mantendoas distantes das ações de assistência médica cometidas à Previdência Social 3 .

O suicídio de Vargas, a vitória das forças conservadoras e a aliança do desenvolvimentismo associado dos anos JK, a introdução da indústria automobilística, criarão um novo campo na área da saúde, distante do salubrismo do Ministério da Saúde e do sistema previdenciário público dos Institutos de Aposentadorias e Pensões: o dos planos privados de saúde. Não foi o fracasso, mas a derrota de uma coalizão de viés nacional-desenvolvimentista e redistributivista que liberou as primeiras demandas não universalistas de um proletariado de novo tipo que surgia em São Paulo.

Projetos universalistas para a saúde são retomados no curto Governo Jango, entrado à força na vice-presidência de Jânio, impulsionado pelo legado trabalhista de Vargas. Não será o proletariado moderno paulista que fará avançar as propostas das "reformas de base". Serão as camadas do proletariado tradicional amparado pela Pre- vidência Social dos IAPS, pela CGT, pelos sindicatos tradicionais, pelas massas do que Singer 4 chamou de subproletariado, trabalhadores de relações informais ou precárias no mercado de trabalho, e pelos trabalhadores rurais e camponeses em luta pela reforma agrária e por direitos sociais. A Conferência Nacional de Saúde de 1963, com suas propostas de municipalização vai ao encontro das necessidades desses segmentos populacionais, sem competir pelos recursos assistenciais dos setores cobertos pelo sistema previdenciário. De novo, forças conservadoras com forte apoio da classe média se articulam, derrubam o governo e apoiam a ditadura militar que durará 21 anos.

O regime militar não ficará distante da necessidade de ampliar sua base social de apoio, como compensação pela supressão das liberdades civis e do controle sindical. De modo autoritário, promove ampla reforma do sistema previdenciário com a unificação dos IAPs em 1966, criando o INPS (Instituto Nacional da Previdência Social). Aquela reforma, ao tempo que afasta as lideranças sindicais que davam suporte ao regime anterior, moderniza o sistema, desenvolve uma nova burocracia, manterá a capacidade de responder aos trabalhadores vinculados aos antigos IAPs. Simultaneamente, são criados mecanismos para fortalecimento das alternativas assistenciais das empresas, abrindo um importante caminho para a ampliação e fortalecimento do setor empresarial da saúde no país 5,6.

Em 1979, o documento do Centro Brasileiro de Estudos de Saúde (CEBES), Democracia e Saú$d e$, abrirá uma agenda política para constituição do chamado Movimento da Reforma Sanitária. Composto por forças do espectro político de esquerda, que associavam mudanças na sociedade ao estabelecimento de políticas sociais de corte universalista inspiradas seja nos modelos bem-sucedidos da social democracia europeia ou dos países socialistas que ainda não viviam sua desarticulação. Aquela agenda não será coincidente com a do movimento sindical que renascia naqueles tempos.

A Nova República, que em 1985 sucede ao regime militar, expande o caminho aberto por alguns governos progressistas municipais e estaduais do final dos anos 1970 e 80 . A coalizão política construída pelo alto com a derrota das eleições diretas, a "Aliança Democrática", deixará a segmentos da esquerda a elaboração das propostas para as políticas sociais. Waldir Pires no Ministério da Previdência Social, Hésio Cordeiro no INAMPS e Sergio Arouca na Fundação Oswaldo Cruz serão sinais daquela abertura. A Oitava Conferência Nacional de Saúde de 1986 será erigida como marco da Reforma Sanitá- 
ria. Contudo, o "proletariado moderno" paulista dela manteve-se praticamente ausente. E cresciam por toda a parte pressões por formas particulares de "asseguramento", inclusive em autarquias e fundações públicas, que acabaram se concretizando.

A expansão de cobertura daquele período à custa de recursos da Previdência Social será responsável pelo que Faveret denominou de "universalização excludente", agravando o afastamento dos setores organizados do proletariado da proposta de um sistema universal. A Constituição de 1988 minimizará normativamente esses efeitos, concebendo a organização da Seguridade Social, com fontes próprias e definidas de financiamento. Porém, assim que proclama$\mathrm{da}$, Sarney promove ampla reforma ministerial e afasta as lideranças reformistas do pacto de governo. A transferência do INAMPS para o Ministério da Saúde dá início à quebra da proposta política da integridade da Seguridade Social. Nova vitória das forças conservadoras que abrirão caminho para a vertigem neoliberal da década de 1990 com Collor e FHC. Aquela década assistirá ao subfinanciamento crescente do sistema de saúde de base pública, criando um estímulo indireto para a expansão dos arranjos privados 8 . A Nona Conferência Nacional de Saúde, organizada no contexto de uma profunda reforma neoliberal do estado brasileiro, ao propor a municipalização como caminho, provocará simultaneamente a abertura de um campo de desobrigação do governo central e uma ampliação da base político-eleitoral, respondendo a demandas assistenciais dos setores desorganizados da população.

O desmanche do Estado brasileiro prosseguirá aceleradamente durante o governo FHC, quando recursos patrimoniais públicos e fiscais são transferidos velozmente para os setores rentistas da burguesia brasileira. A vitória de Lula, como aponta Singer 9 com clareza, em um primeiro momento representa uma transição "conciliadora” a que seguirá, em seu segundo mandato, à expressão política do subproletariado. A análise de Singer permite entender o caráter reformador dos governos sul-americanos da Argentina, Uruguai, Paraguai, Equador, Bolívia e Venezuela. Permite também entender a perplexidade de setores da esquerda com um reformismo, que embora moderado, açula as iras das burguesias conservadoras que conspiram diuturnamente para a derrocada dessas lideranças para retomar o aprofundamento da captura de recursos fiscais e patrimoniais desses países.

A persistência e agudeza da crítica deve ser preservada para garantir os avanços sociais e políticos, mas não conseguirá formar maiorias sólidas que garantam solidez na democracia e avanços significativos no cotidiano das vidas dos contingentes mais pobres das populações. Singer não nega a luta de classes, mas a contextualiza no horizonte do real para fortalecer a luta política e garantir avanços nas políticas desenvolvimentistas e redistributivistas.

Em suas palavras, "O lulismo, por sua vez, alterou a base social do PT e favoreceu, em particular no segundo mandato, a aceleração do crescimento econômico com diminuição da desigualdade, sobretudo mediante a integração do subproletariado à condição proletária via emprego formal. No plano ideológico, isso trouxe, outra vez, à tona a gramática varguista, que opunha o 'povo' ao 'antipovo"' 9 (p. 16).

Enfim é preciso, como propôs Furtado 10 (p. 64), que "o principal objetivo da ação social [deixe] de ser a reprodução dos padrões de consumo das minorias abastadas para ser a satisfação das necessidades fundamentais do conjunto da população e a educação concebida como desenvolvimento das potencialidades humanas nos planos ético, estético e da ação solidária".

1. Foucault M. As palavras e as coisas. São Paulo: Martins Fontes; 2000.

2. Donnangelo MCF. Medicina e sociedade. São Paulo: Pioneira Editora; 1975.

3. Hamilton W, Fonseca C. Política atores e interesses no processo de mudança institucional: a criação do Ministério da Saúde em 1953. Hist Ciênc Saúde-Manguinhos 2003; 10:791-825.

4. Singer P. Dominação e desigualdade. Rio de Janeiro: Paz e Terra; 1981.

5. Oliveira JAA, Teixeira SMF. (Im)Previdência Social: 60 anos de história da Previdência no Brasil. Rio de Janeiro: Editora Vozes/ABRASCO; 1986.

6. Cordeiro H. As empresas médicas: as transformações capitalistas da prática médica. Rio de Janeiro: Edições Graal; 1984.

7. Centro Brasileiro de Estudos de Saúde. A questão democrática na área da saúde. Saúde Debate 1980; (9):11-3.

8. Noronha JC, Soares LT. A política de saúde no Brasil nos anos 90. Ciênc Saúde Coletiva 2001; 6:44550 .

9. Singer AV. Os sentidos do lulismo. Reforma gradual e pacto conservador. São Paulo: Companhia das Letras; 2012.

10. Furtado C. O capitalismo global. São Paulo: Paz e Terra; 1998. 